\title{
Combined EUS and EBUS are complementary methods in lung cancer staging: Do not forget the esophagus
}

Authors

Institutions
Peter Vilmann ${ }^{1}$, Paul Frost Clementsen²

${ }^{1}$ GastroUnit, Department of Surgery, Herlev University Hospital, DK 2730 Herlev, Denmark

${ }^{2}$ Centre for Clinical Education, Rigshospitalet, 2100 Copenhagen, University of Copenhagen and the Capital Region of Denmark and Department of Respiratory Medicine, Gentofte University Hospital, 2900 Hellerup, Denmark

\section{Bibliography}

DOI http://dx.doi.org/

10.1055/s-0034-1392786

Endoscopy International Open

2015; 03: E300-E301

(c) Georg Thieme Verlag KG

Stuttgart · New York

E-ISSN 2196-9736

Corresponding author

Peter Vilmann, MD, PhD,

DMSci

GastroUnit, Department of Surgery,

Herlev University Hospital

DK 2730 Herlev

Denmark

Phone: +4538682164

Peter.Vilmann@regionh.dk

\section{Combined EUS and EBUS are complementary methods in lung cancer staging: Do not forget the esophagus}

Endoscopic ultrasound (endobronchial ultrasound-guided transbronchial needle aspiration [EBUS-TBNA] and transesophageal ultrasoundguided fine needle aspiration [EUS-FNA]) can be performed in an outpatient setting under local anesthesia with mild sedation. The procedures are well established for diagnosis and staging of a variety of diseases, such as lung cancer [1 -3]. Accurate staging of non-small cell lung cancer (NSCLC) is crucial for allocation to surgical treatment. By using endoscopic ultrasound, surgical staging procedures can be avoided in a considerable proportion of patients with NSCLC. In short, EUS is excellent for the left and lower paraesophageal structures plus structures under the diaphragm, whereas EBUS provides access to structures close to the large airways on both sides. Thus the two procedures are complementary (० Fig. 1) [4].

Currently no single endoscope offers the benefits of both endobronchial and transbronchial access. Compared to EBUS, EUS has many advantages. EUS is better tolerated (no cough), the ultrasonic window angle is larger (150-180 versus $50-60$ degrees with EBUS), the ultrasonic image is better due to higher resolution, it allows better visualization of small structures, the operator can orientate independent of an endoscopic view with secretions, and the transducer is in close contact with the target, owing to endoscopic suction with deflation of the esophageal lumen. With EUS, there are also no hard cartilage rings interposed between the needle and the target and needle maneuverability is better with improved targeting due to an "elevator." All of these benefits are outweighed by a single disadvantage: the psychological barrier to use of EUS that exists among many-but not all-thoracic physicians. The way to overcome this barrier is to let a thoracic physician perform EUS with the smallest EBUS endoscope, that is, to perform a so-called EUS-B procedure $[5,6]$ even if the equipment is not designed for the purpose and therefore, in many respects, inferior compared to EUS-FNA.

In their current paper, Meena and Bartter performed a retrospective comparison of EUS-B and EBUS in a total of 155 procedures and found that EUS-B was faster, patients needed less sedation and oxygen, and the time to discharge was shorter, whereas the diagnostic yield was the same. The authors conclude that EUS is the procedure of choice when applicable, meaning that, for example, EUS-B should be preferable to EBUS in a patient with a suspicious lymph node station 7 or $4 \mathrm{~L}$. It must be remembered, however, that in the majority of cases, choosing one method over the other is not the issue because EBUS and EUS are complementary and can be performed in a single session [4].

It should be mentioned that, for obvious reasons, several of the advantages of EUS listed above are not achievable with EUS-B. One example is superior ultrasonic visualization. It must also be noted, that in the current study, regions under the diaphragm relevant for staging of NSCLC ( $\bullet$ Fig. 1) could not be reached with the relatively short EUS-B technique, meaning that EUS does not get its full credit as a comparator in the study. Further, patient preference also have been explored by asking whether an individual preferred a foreign body in the airway or in the esophagus, although the answer seems predetermined.

If thoracic physicians are not to be left behind in terms of advancements in endoscopic ultrasound, it is mandatory that necessary education and training be established for EUS as well as EBUS, including theoretical courses, simulator-based education, and clinical training plus valid assessment of all three elements [7-10]. But do not forget the esophagus! 


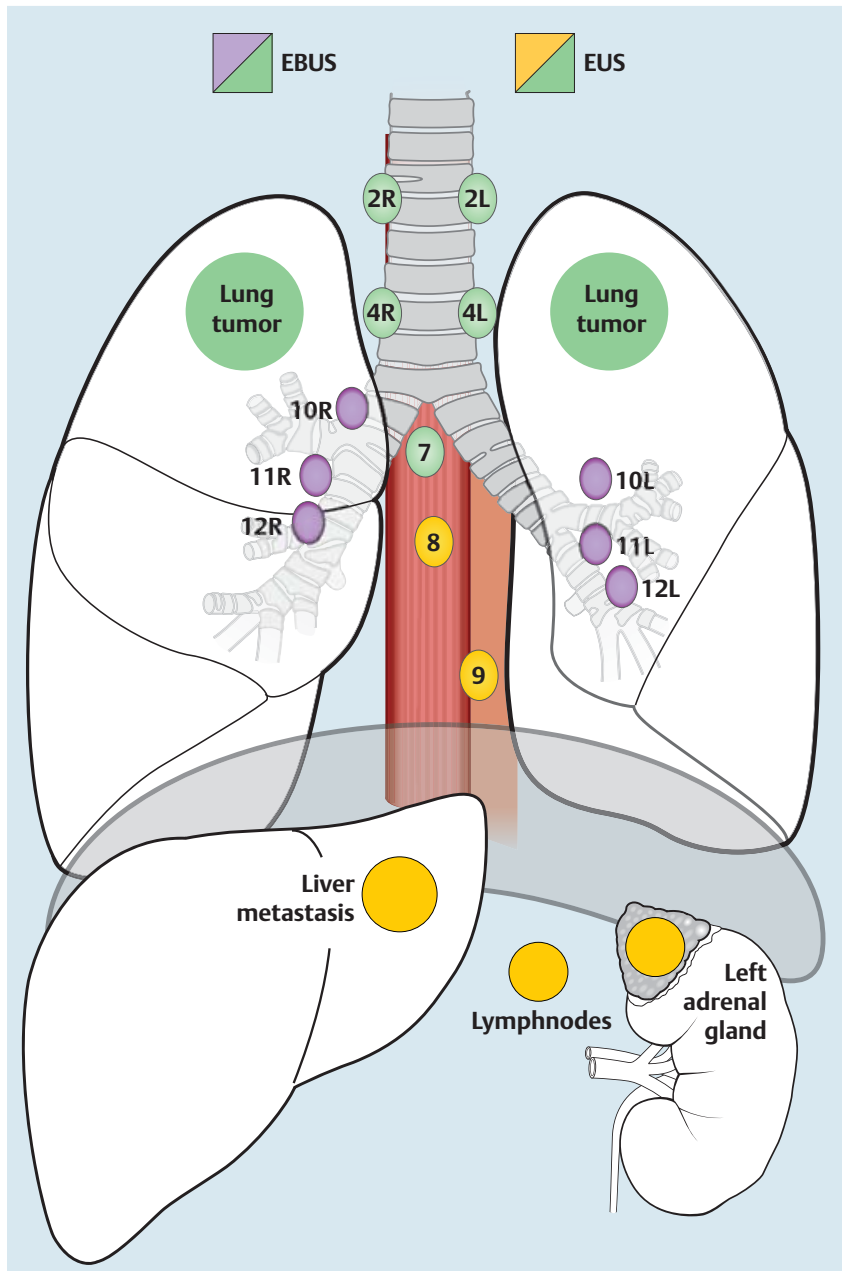

Fig. 1 Illustration of mediastinal lymph node stations and abdominal regions reached by EUS and EBUS, respectively (Mountain-Dressler classification).

\section{References}

1 Vilmann P, Annema J, Clementsen P. Endosonography in bronchopulmonary disease. Best Pract Res Clin Gastroenterol 2009; 23: 711 - 728

2 Annema JT, van Meerbeeck JP, Rintoul RC et al. Mediastinoscopy vs endosonography for mediastinal nodal staging of lung cancer: a randomized trial. JAMA 2010; 304: 2245-2252

3 von Bartheld MB, Dekkers OM, Szlubowski A et al. Endosonography vs conventional bronchoscopy for the diagnosis of sarcoidosis: the GRANULOMA randomized clinical trial. JAMA 2013; 309: 2457-2464

4 Vilmann P, Clementsen PF, Colella $S$ et al. Combined Endobronchial and Esophageal Endosonography for the Diagnosis and Staging of Lung cancer. A Clinical Guideline by the European Society of Gastrointestinal Endoscopy (ESGE), European Respiratory Society (ERS) and European Society of Thoracic Surgeons (ESTS). Endoscopy 2015; 47: c1 DOI 10.1055/s-0034-1392453 Epub 2015 Jun 10

5 Hwangbo B, Lee GK, Lee HS et al. Transbronchial and transesophageal fine-needle aspiration using an ultrasound bronchoscope in mediastinal staging of potentially operable lung cancer. Chest 2010; 138: 795 802

6 Herth FJ, Krasnik M, Kahn N et al. Combined endoscopic-endobronchial ultrasound-guided fine-needle aspiration of mediastinal lymph nodes through a single bronchoscope in 150 patients with suspected lung cancer. Chest 2010; 138: 790 - 794

7 Konge L, Vilmann P, Clementsen P et al. Reliable and valid assessment of endoscopic ultrasonography and fine needle aspiration competence in mediastinal staging of non-small cell lung cancer. Endoscopy 2012; 44: $928-933$

8 Konge L, Annema J, Vilmann P et al. Transesophageal Ultrasonography for Lung Cancer Staging: Learning Curves of Pulmonologists. J Thorac Oncol 2013; 8: 1402-1408

9 Konge L, Annema J, Clementsen $P$ et al. Using virtual-reality simulation to assess performance in endobronchial ultrasound. Respiration 2013; 86: $59-65$

10 Sert MMS, Clementsen PF, Annema JT et al. Development and validation of a theoretical test in endosonography. Respiration 2014; 88: 67-73

Competing interests: Dr. Vilmann is a consultant at MediGlobe, $\mathrm{GmbH}$ in Germany, producing EUS and EBUS needles. 